\title{
Causes of Deprivation of Elementary Education in Children Living in Slums
}

\author{
B. Razia
}

\section{ABSTRACT}

Education plays an important role in uplifting the Socio-economic Status of a society. Significant proportions of urban poor population in India live in slum areas and are deprived of education. Large number of children living in slums (age group of 6-14 years) are out of school due to varied reasons. The researcher focused the study on the causes of non-enrolment and dropout of such deprived children. Incidental sampling technique was employed to collect the data from various households of 8 different slum localities of Aligarh city, India. Data collected from the parents through Structured Interview Schedule indicates that $43.06 \%$ children between the age group of 6-14 years have never enrolled in schools while $33.57 \%$ of total children dropped out due to varied reasons. The causes underlying nonenrolment and dropout of children living in slums have been discussed in detail in this paper.

Keywords: Dropout, Elementary Education, Non-enrolment, Slums.
Published Online: July 21, 2021

ISSN: $2736-4534$

DOI : $10.24018 /$ ejedu.2021.2.3.133

\section{B. Razia *}

Department of Education, Aligarh Muslim University, India.

(e-mail: razianaushad.amu@ gmail.com)

*Corresponding Author

\section{INTRODUCTION}

Education plays an important role in uplifting the Socioeconomic Status of a society. Lack of education accompanied with extreme poverty often leads to pathetic conditions of the people which can be commonly seen in the urban neighbourhoods in the form of slums. Significant proportions of urban poor population in India live in slums. As per Census 2011 [1], approximately 17\% of urban population reside in slum areas in India. Mishra and Banerjee [2] reiterates that "poor educational development in slums is both the result and consequence of poverty and low income". Slums are the "areas of housing built on government or private land characterised by low-quality housing, overcrowding, poverty, poor environmental conditions, and limited access to services" Cameron [3]. According to Seetharamu [4], slums have become the inevitable by products of the process of urbanisation. They grow over years defying all attempts at planned urban development. "Various measures were suggested in different policies and five-year plans for the development of rural and backward areas, but no concrete strategies were evolved to look into the educational problems of urban deprived. The average socio-economic indicators, like per capita income, infant mortality rate, literacy level, enrolment of the school going children, are much better in urban areas as compared to the national average, but the same is not true of the slum areas. The situation in some slum areas is even worse than many rural areas" Agarwal and Chugh [5]. These are the most vulnerable and isolated populations who are also deprived of education due to many reasons. Many studies indicate some common reasons such as poverty, ill health, need of children to be engaged in domestic chores, living in deprived places with lack of access to education etc. that keeps them away from education. People residing in slums are often engaged in manual and odd jobs, education is often not considered important. Lack of quality schools in the vicinity of slums is another important and serious issue. The maintenance of the supply side limitations and discrimination in the provision of educational communications and infrastructure are also most important factors that affect the demand and supply of education among the slum dwellers Agarwal \& Chugh [5]. Right to Education Act, 2009 in India envisages free and compulsory education to all the children till they complete the age of 14 years. It becomes vital to ensure that all the children dwelling in the poor urban areas get enrolled, attend regularly, ensure participation, and complete a minimum term of universal compulsory elementary education.

\section{REVIEW OF RELATED LITERATURE}

Review of related studies show that some studies have been conducted in India from past two decades focusing on educational status of slum residents Rahaman [6]; Lahon [7]; Mohanty [8] and Tsujita [9]. Rahaman [6] limited his study on the slum residents of Kalyani Municipality. The researcher observed that people were living in moderately poor condition and many of them were of low level of educational achievement and were also deprived of literacy. The researcher suggested that the "government slogan Education for All needs to be launched in slum areas. Their effort is also needed to provide free education for accelerating the literacy levels in the surveyed areas. For that the local urban govt. i.e., the Kalyani Municipality should take the lead in organising concerted and coordinated efforts 
to mobilise the local resource and the people along with the governmental and NGOs for solving the existing problems of under education in the slums that may improve the quality of life" while Lahon [7] focused his study on urban slums of Guwahati City. The researcher reported that only $40 \%$ of children were regularly attending schools. The students gave different reasons for attending the school were. Some children took admission for getting free text books, uniforms, bag and mid-day meal provided by Sarva Shiksha Abhyan programme. $40 \%$ of students said that medium of teaching was a problem. $60 \%$ of children complained that the school conditions were not good. Most of the children opined that they do not get time and space for study at their home (95\%) and all the children viewed that they do not get any sort of help in their study by their parents. Students did not receive any scholarship as they were unaware of governmental policies. In a similar study Agarwal and Chugh [5] found that slums were lacking the necessary physical and civic amenities, and either were lack of or with poor schooling facilities. The achievement of the slum children was much below the expected levels in subjects like math and language.

Studies also attempted to find the enrolment rate and dropout rate of children living in slums. Variations were observed for enrolment rates in different slum areas in the country. Mohanty [8] found 40\% enrolment among children at elementary level while Nath [10] found $57.82 \%$ enrolment rate in which $54.57 \%$ children attended schools regularly and the rest $3.25 \%$ were not regular to schools while Tsujita [9] concluded that just over $50 \%$ of the children residing in slums are in school in Delhi contrary to these findings Shah and Sen [11] observed that enrolment rate was quite high. Most of the studies also found high dropout rate among slum children. Mohanty (2014) in a study observed high level of dropout rate (55\%) similar to the findings of Tsujita [9] and Shah and Sen [11] while Nath [10] in his study observed only $6 \%$ dropout cases. Class wise analysis indicated that the quality of education being provided was poor due to which drop out cases were more Shah and Sen [11]. Studies also indicate that poverty, school as well as home related factors emerged as causal factors for dropout and never enrolment among deprived children Mohanty [8]. Another study focused on causal factors of late admission many factors like migration from rural areas to slums, lack of school capacity to include every student, lack of birth certificate at the side of parents etc. Even poverty was also one of the major reasons of students unable to attend the school [9].

The investigator while conducting review of related literature found dearth of studies pertaining to educational problems of children living in slums of Uttar Pradesh especially Aligarh. Uttar Pradesh constitutes 9.5\% share of slum population to total slum population of India. There are 42,682 households in slum areas in Aligarh Municipal corporation with a population of 258,841 (Census 2011) which constitutes $29.6 \%$ of total population of the city which is quite larger share. Hence a need was felt to study the causes of non-enrolment and dropout of children in school living in extreme pathetic conditions in slums.

Following objectives were framed for the study:

- To understand the Socio-economic Status of the children living in slums.
- To study the school status of children (6-14 years age group) residing in slums.

- To examine the reasons for non-enrolment of children living in slums.

- To identify the causal factors for dropping out of school children residing in slums.

\section{Methodology}

Quantitative approach with Survey method was used to collect the data from the parents residing in slums. Incidental sampling technique was employed by the researcher to draw information from various households of 8 different slum localities of Aligarh city. Data was collected through selfprepared 'Structured Interview Schedule' to gather information regarding various aspects such as socioeconomic status of slum residents, education of parents, causes of non-enrolment and dropout of children. The investigator personally visited various slum localities, attempted to build rapport with the respondents and collected the data. The study is delimited to slum children of 6-14 years age group in Aligarh city.

\section{DATA ANALYSIS AND INTERPRETATION}

Statistical analysis of the collected data was done through Percentages which has been tabulated and interpreted in the following sections.

\section{A. Socio-economic Status of Slum Residents}

The Table I indicates the socio-economic status of slum residents living in urban slums. It is clear from the table that $27.57 \%$ of the selected slum residents (parents having children of 6-14 years of age) are living in joint families, $72.43 \%$ are having nuclear families and $28.9 \%$ of them are single parent families. It is also evident that only $10.52 \%$ of the slum residents are having single child families, $31.12 \%$ are with 2 to 3 children, $36.13 \%$ of the families are having 4 to 6 children and $22.23 \%$ are with more than 6 children.

The table further indicates that slum residents are engaged in different odd jobs for their means of livelihood mainly as beggars $(19.02 \%)$, rag pickers $(21 \%)$, rickshaw pullers $(30.2 \%)$ daily wagers $(12.7 \%)$ and housekeepers (19\%).

As far literacy rate of the parents of slum children are concerned, only $41.9 \%$ are literates and the rest $58.1 \%$ are illiterates.

TABLE I: SOCIO-ECONOMIC STATUS OF SLUM RESIDENTS

\begin{tabular}{ccc}
\hline \multicolumn{2}{c}{ Socio-economic status } & Percentage \\
\hline \multirow{2}{*}{ Family Type } & Joint & $27.57 \%$ \\
& Nuclear & $72.43 \%$ \\
& Single parent family & $28.9 \%$ \\
Number of & 1 & $10.52 \%$ \\
children/family & $2-3$ & $31.12 \%$ \\
& $4-6$ & $36.13 \%$ \\
& More than 6 & $22.23 \%$ \\
Means of & Begging & $19.02 \%$ \\
livelihood & Rag picking & $21 \%$ \\
& Rickshaw Pulling & $30.2 \%$ \\
& Wager on daily basis & $12.7 \%$ \\
Education & House keeping & $19 \%$ \\
& Literate & $41.9 \%$ \\
\hline
\end{tabular}




\section{B. School Status of children (6-14 years) residing in Slums}

The Table II indicate that only $22.63 \%$ of total children between the age group of 6-14 years have enrolled in various schools while $43.76 \%$ never enrolled cases can be seen. It is also clear that $33.61 \%$ of children living in slums dropped out of the school due to varied reasons. It is further made clear from Fig. 1.

TABLE II: SCHOOL STATUS OF CHILDREN (6-14 YEARS) RESIDING IN

\begin{tabular}{ccc} 
& SLUMS & \\
\hline School Status & Number & Percentage \\
\hline Enrolled & 31 & $22.63 \%$ \\
Never Enrolled & 59 & $43.76 \%$ \\
Drop outs & 46 & $33.61 \%$ \\
Total & 137 & $100 \%$ \\
\hline
\end{tabular}

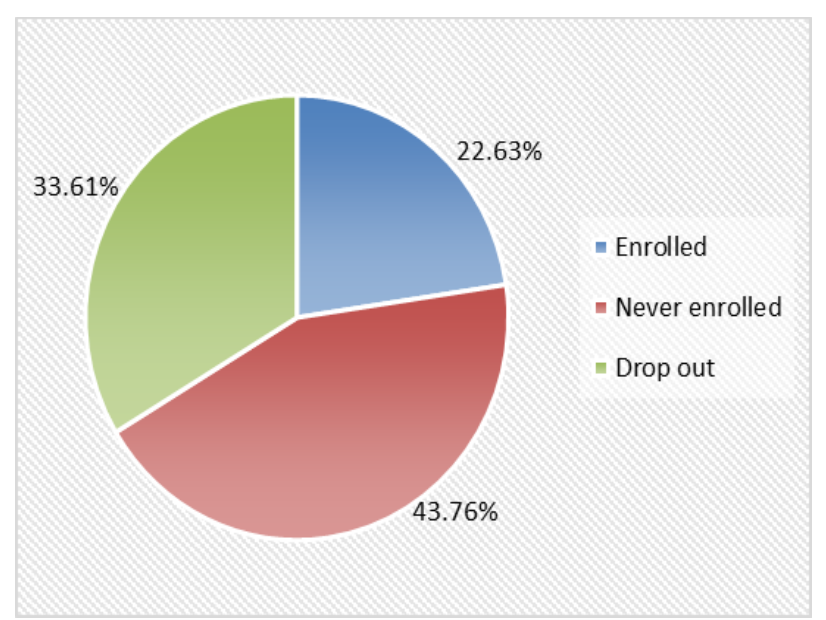

Fig. 1. School status of children living in Slums.

\section{B. Reasons for Non-Enrolment of Children Living in Slums}

One of the objectives was to trace the reasons for nonenrolment of children in schools. The parents gave multiple reasons. It is evident from Table III that $81.08 \%$ of parents opined that poverty is one of the major causes for nonenrolment of children. Apart from poverty, around 52.13\% of parents said that looking after younger siblings was the main job of the children while they are at work due to which children were not enrolled in schools. Around $35.96 \%$ of parents expressed that non availability of schools as one of the reasons while $47.53 \%$ viewed that their child is being engaged for domestic help. Some parents indicated health issues as one of the reasons for non-enrolment (31.47\%) while $11.02 \%$ added some other reasons like lack of awareness, child labour, feeling of insecurity, etc.

TABLE III: REASONS FOR NON-ENROLMENT OF CHILDREN LIVING IN

\begin{tabular}{ccc} 
& SLUMS & \\
\hline Reasons & Percentage & Rank \\
\hline $\begin{array}{c}\text { Poverty } \\
\text { Looking after younger }\end{array}$ & $81.08 \%$ & 1 \\
siblings & $52.13 \%$ & 2 \\
Non-availability of & $35.96 \%$ & 4 \\
schools & $47.53 \%$ & 3 \\
Domestic work & $31.47 \%$ & 5 \\
Health problems & $11.02 \%$ & 6 \\
Other reasons & & \\
\hline
\end{tabular}

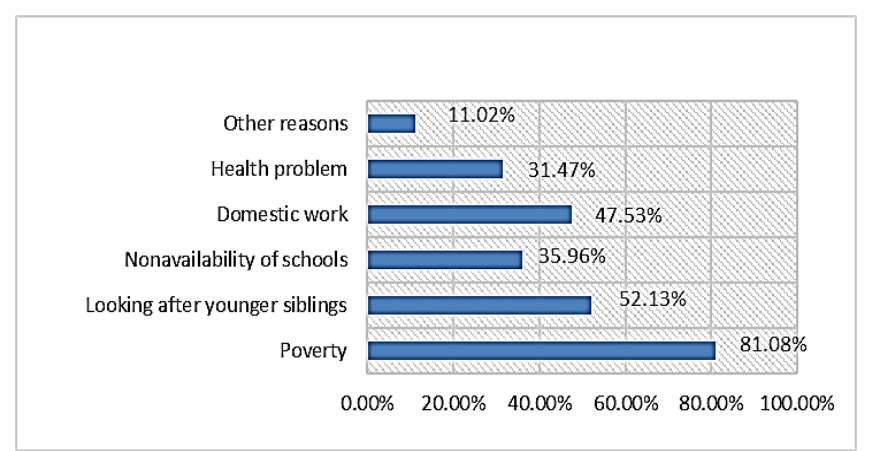

Fig.2. Reasons for non-enrolment of slum children.

\section{Reasons for Dropping out of School}

The investigator tried to find out the reasons for school drop out of children residing in slums. It is evident from the table that $29.7 \%$ of the parents opined poverty as the main cause while $21 \%$ said that consistent poor academic performance of their wards forced them to leave the schools. Lack of interest in studies emerged as the third main causal factor $(19.1 \%)$ and distance of School from home (13.1\%) was the fourth important cause for leaving the school. Apart from the said reasons poor school facilities $(8.8 \%)$ and indifferent attitude of teachers (3.7\%) and problem with medium of teaching $(3.4 \%)$ are also the factors responsible for school dropouts among slum children. Around $1.2 \%$ of the parents gave some other reasons like migration, lack of motivation, poor health conditions of their children etc.

TABLE IV: REASONS FOR DROPPING OUT OF SCHOOL

\begin{tabular}{ccc}
\hline Reasons & Percentage & Rank \\
\hline Poverty & $29.7 \%$ & 1 \\
Distance of School from home & $13.1 \%$ & 4 \\
Poor facilities in school & $8.8 \%$ & 5 \\
Attitude of teachers & $3.7 \%$ & 6 \\
Medium of Teaching & $3.4 \%$ & 7 \\
Poor Academic performance & $21 \%$ & 2 \\
Lack of interest & $19.1 \%$ & 3 \\
Other reasons & $1.2 \%$ & 8 \\
\hline
\end{tabular}

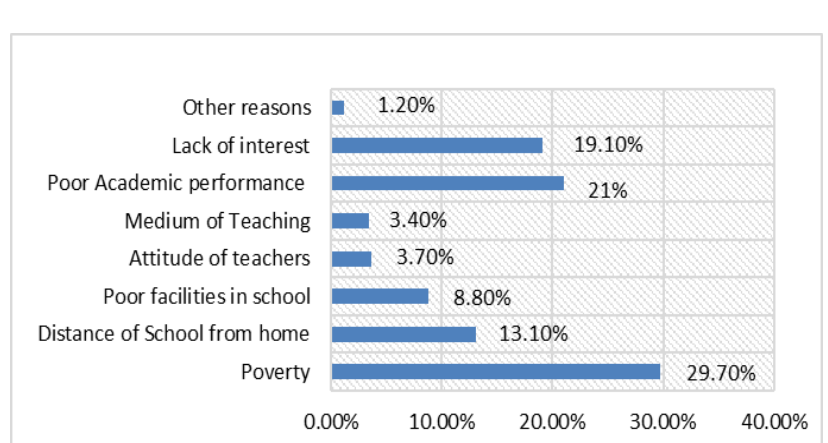

Fig. 3. Reasons for dropping out of school.

\section{DISCUSSION}

The Analysis of Socio-economic characteristics of slum residents of Aligarh, India presents a dismal picture with $58 \%$ of families having more than 4 children per family. Most of them live in extreme poverty and are engaged in different odd jobs for their means of livelihood mainly as beggars $(19.02 \%)$, rag pickers $(21 \%)$, rickshaw pullers $(30.2 \%)$ daily wagers and housekeepers $(19 \%)$. The literacy rate among them is also very poor $(41.9 \%)$. The literacy rate 
$(41.9 \%)$ is much less than the national average which is a matter of serious concern.

The study brought into light that only $22.63 \%$ of children between the age group of 6-14 years have enrolled in various schools (much below the national average) and also found that $43.76 \%$ have never enrolled similar to the findings of Nath [10] who observed $36.06 \%$ non-enrolled cases in selected slums of Kolkata. In the present study the researcher got multiple reasons for non-enrolment of children. Parents viewed poverty as the major cause for not enrolling their wards to schools similar to the observations of Nath [10], and Kumar [12]. Second main reason given was 'looking after younger siblings while they are at work'. Some said that children are not admitted to schools as they required at home engaging in domestic work. Most of the parents also opined that non availability of schools $(35.96 \%)$ as one of the causes of non-enrolment of children. $31.47 \%$ of the parents said that their children suffer from malnutrition and have health problems due to which they were not enrolled in schools.

The study shows that $33.61 \%$ of the children drop out of the school due to various reasons. Personal factors coupled with school related ones emerged significant in this regard. About $29.7 \%$ of the parents opined poverty as major cause as observed by Azim [13] in a study conducted on slum dwellers of Kisanwadi, Baroda. Similar results were obtained by Nath [10] for slums of Kolkata. Poor academic performance and lack of interest in studies emerged as the second and third important cause of school dropouts. Distance of School from home $(13.1 \%)$ is the fourth important cause that compels children to leave the school similar to the findings of Agarwal and Chugh [5]; Azim [13]. Poor school facilities and indifferent attitude of teachers and problem with medium of teaching are the fifth, sixth and seventh causal factors responsible for school dropouts among slum children in line with the findings of Agarwal and Chugh [5]; Seetharamu [6]; Lahon [7] and Sarma, et al. [14] who observed school related factors like medium of teaching, lack of physical facilities affects school enrolment and drop-out of children from school. Shah and Sen [11] also found that dropout cases become higher when the quality of education lowers.

\section{CONCLUSION}

The paper highlights the educational problems of slum children of Aligarh in relation to non-enrolment and dropout. Poverty emerged as the major causal factor for nonenrolment of children living in urban slums apart from other hindering aspects like looking after younger siblings, nonavailability of schools within walkable distance and engaging in domestic chores. Similarly, poverty, poor academic performance, and lack of interest in studies emerged as the major reasons for dropping the school. This is a matter of serious concern which need due attention from various stake holders. More focused steps are required to facilitate the large chunk of the urban poor children living in slum areas and facing inequalities in socio-economic and educational aspects. In order to make the concept of 'Education for all' a grand success, the problems of slum children with regard to non-enrolment and dropouts has to be taken seriously by all the stakeholders including the Government, School Administrators, teachers, NGO's etc.

\section{REFERENCES}

[1] Census 2011, Primary census abstract data for slum (India \& States/UTs

TownLevel).https://censusindia.gov.in/2011census/population_enum eration.html.

[2] Mishra V.K., \& Banerjee A. (2020) Socio-economic deprivation among slum dwellers: A case study of migrants in slums of Allahabad. In: Banerjee A., Jana N., Mishra V. (eds) Population Dynamics in Contemporary South Asia. Springer, Singapore. https://doi.org/10.1007/978-981-15-1668-9_8.

[3] Cameron, S. (2010). Access to and exclusion from primary education in slums of Dhaka, Bangladesh. Research Monograph. Centre for International Education: University of Sussex. http://www.createrpc.org/pdf_documents/PTA45.pdf.

[4] Seetharamu, A. S. (1983). Education in Slums. New Delhi: Ashish publishing.

http://203.200.22.249:8080/jspui/bitstream/123456789/12290/1/Educ ation_in_Slums.pdf.

[5] Agarwal,Y.P., \& Chugh,S (2003). Learning achievement of slum children in Delhi, NIEPA, Occasional Paper. http://www.niepa.ac.in/download/Publications/Occasional\%20Paper34schugh.pdf.

[6] Rahaman, M. (2018). Demographic structure and educational status of slum population in Kalyani municipality, West Bengal. The Research Journal of Social Sciences 9 (10).

[7] Lahon, S. (2017) Educational status and level of health awareness of the children of urban slums with special reference to Guwahati city- A study. International Journal of Applied Research, 3(3): 680-686. http://www.allresearchjournal.com/archives/2017/vol3issue3/PartK/3 -3-137-703.pdf.

[8] Mohanty, P. (2014). Non-enrollment and dropout in elementary Education - a study of scavenger's children Living in urban slums of Lucknow and Kanpur. European Academic Research.1(12): pp. 56645677.

[9] Tsujita, Y. (2009) Deprivation of education: a study of slum children in Delhi, India. Background paper prepared for the Education for All Global Monitoring Report 2010 Reaching the marginalized. Retrieved from https://unesdoc.unesco.org/ark:/48223/pf0000186592.

[10] Nath, I (2010). Critical study of the problems of non-enrollment, dropout \& nonattendance of children at primary stage of education in urban slums of Kolkata: a case study." Unpublished Thesis: Calcutta University. India.

[11] Shah,M., \& Sen,S (2008). Education mapping in a slum area: an analysis of the dynamics of demand and supply. CCS Working Paper No. 201 Summer Research Internship Programme 2008 Centre for Civil Society. Retrieved from https://ccs.in/internship_papers/2008/Education-mapping-of-a-slumarea-201.pdf.

[12] Kumar, M. (2012). Enrolment ratio of school going children in slum area of Panipat city with relation to certain demographic variables. International Indexed \&Referred Research Journal,3(32).

[13] Azim, S.R. (1983). A study of life style of slum-dwellers and its relation with education. Unpublished Thesis: Maharaja Sayairao University of Baroda, Department of Education, CASE. http:/hdl.handle.net/10603/59123.

[14] Sarma, H. N., Bineeta \& Sharma, D. (1991). Identification of the problems of primary education. In Buch, M.B. (ed): Fifth Survey of Educational Research, 1988- 92, Vol 2, NCERT, New Delhi, pp. 1159-60. 